\title{
Privatizing Public Research Universities: Wealth Creation as a Laudable Goal and Not a Sleazy Perversion
}

\author{
R. W. Trewyn
}

Vice Provost for Research and Dean of the Graduate School

President, KSU Research Foundation

Kansas State University

$\mathrm{S}$ tate financial support for higher education has been declining nationally for years. Seldom has it kept pace with annual increases in either inflation or state revenue. During the economic boom of the 1990s, state revenues in Kansas were substantially higher than inflation; annual state budgets for higher education were not. As a result, the state proportion of the operating budget at Kansas State University and other Kansas public institutions declined annually, a trend consistent across most public universities in America. Clearly, privatization of public universities is a reality that institutions now must recognize and act upon.

20th-Century Mission Impossible: Creating Wealth in Public Universities Research universities have been undergoing a myriad of changes in recent years, as I detailed in my 2004 Merrill article. ${ }^{1}$ As I noted then, "institutions not moving forward strategically - changing with the timeswill soon be left behind, becoming ever less relevant and underutilized." Even so, there is great pressure on most university campuses to maintain the status quo. College faculties are reluctant "merchants of change," but if they will lend their assistance, privatization can be turned in their favor.

Since the enactment of the BayhDole Act in 1980, most research universities have become more focused on technology transfer, i.e., they have attempted to capture value on the intellectual property (IP) developed at the institution. "Prior to 1980, the federal government retained title to IP created on federally funded research projects, and the IP was lost to commercialization. The Bayh-Dole Act changed that by allowing universities to retain title and requiring that commercialization efforts be explored."2 Nonetheless, few technology transfer offices are major profit centers supporting university privatization.

There are exceptions though, and the University of Wisconsin is a great example. Intellectual property returns to that university have been in the millions of dollars annually for decades-from Warfarin, Vitamin D, and a few other big-dollar patents-beginning well in 
advance of Bayh-Dole. Wisconsin is one of but a few success stories, however.

For those public research universities that have made money, the income has generally been based on a small number of technologies, and wealth creation has not been an institutional mission. In fact, creating wealth - at a public university - tended to be an alien and perverse concept to most faculty members during the $20^{\text {th }}$ century.

\section{Creating Wealth in 21st Century Public Universities: Mission Possible?}

In the new millennium, the recognition by faculty, not just university administrators, of the financial challenges facing their universities has increased appreciably. International conferences held on the topic-for example, the Glion Colloquium in Switzerland in 2003 on Reinventing the Research Universityillustrate the level of concern. Reinvention (if it's real) will not be a trivial endeavor for institutions steeped in medieval traditions.

There is hope. The then-Chancellor of North Carolina State University, Marye Anne Fox (now chancellor of the University of California San Diego), wrote in her Glion reinvention article on financing: "American public higher education has entered a new era characterized by rapidly increasing enrollment, declining state support, and rising expectations for involvement in wealth creation." 3 Higher education is moving forward when a university chancellor can talk openly about the need for wealth creation.

But, how does a public university institutionalize the new goal of creating wealth? And creating wealth for whom?
Typically, university deliberations about wealth creation (if they occur) focus on creating wealth for someone else, not the university. Most such discussions revolve around technology-based economic development and the role universities can play in that process ... offshoots of Bayh-Dole.

Occasionally, faculty entrepreneurs are among the financial beneficiaries of university commercial spinout ventures, but an institution of higher education isn't expected to become wealthy in the process. It might share in some portion of the revenues, possibly, but it should certainly not become tarnished by affluence.

And why not? Wouldn't that provide needed resources for privatization reinvention?

States are backing off in their tax support of higher education. That makes privatization a $21^{\text {st }}$ century reality, and as a result, universities must become more entrepreneurial.

Given the new reality, why must public universities be entrepreneurial on the cheap? Why not think big? What's wrong with creating wealth for the purpose of bankrolling privatization and enhancing the institution's financial bottom line significantly?

Sure it might not work. The Colorado Institute of Technology found that out, having to close its doors in 2006 after just 6 years in existence. ${ }^{4}$ Training 10,000 high tech workers in an industrial sector that lost 40,000 jobs is less than optimal and not very profitable.

\section{Rational Exuberance: Seeking “Mission Compatible" Wealth}

Nevertheless, there are some economic strategies that universities 
might consider to create wealth. One particularly intriguing approach has been described as "rational exuberance" by Michael Mandel, a philosophy touted for an economy based on innovation. ${ }^{5}$ An exuberant growth economy is driven by new technologies, and new technologies are developed routinely at public research universities. They are what such universities are all about, especially when the new mission of economic development is factored in. Moreover, exuberant economic growth sustains high rates of employment for a college educated workforce, and "jobs for graduates" is a vital university outcome metric.

Cautious economic growth-the alternative-encourages capital accumulation and savings, but because there's less innovation, routine technologyrelated jobs move offshore-to China, India, and elsewhere. U.S. jobs diminish for those with a college education. Thus, public research universities are ill advised to advocate a cautious approach. That being the case, why couldn't universities adopt rational exuberance as an economic philosophy by which to operate henceforth?

In all probability, the biggest impediment is going to be the non-risk taker mentality that permeates most universities. As noted by Rational Exuberance author Michael Mandel: “An innovative economy demands the willingness to experiment, the ability to take risks and commit money into promising opportunities, and the intestinal fortitude to fail and keep going." 6 The "intestinal fortitude" attribute is likely to present problems at most public research universities . . . at least if the fail part occurs within the institution.

Of course, the failure outcome might be lessened by adopting a General George S. Patton leadership principle touted for corporations by Alan Axelrod: "You are never beaten until you admit it. Hence, don't." 7 So perhaps the way for universities will be a melding of Mandel's and Patton's philosophies: Take risks, never admit defeat, never fail-"irrational exuberance."

Such an amalgamation isn't publishable though. Irrational Exuberance is already the subject of a book by an economist more risk averse and less enthusiastic than Mandel. 8

\section{Creating an Entrepreneurial University Culture}

Regardless of the reinvention model they choose, public research universities must become more entrepreneurial if they are going to survive privatization. The following six common principles will likely be required:

- Challenging the Status Quo: In the absence of external pressures to transform, the status quo tends to prevail. Therefore, it is incumbent on university leaders to apply necessary force in the new direction. Reinvention is going to require defined strategies and tactics. Once those are identified, university leaders must lead, monitor followthrough, and continuously adjust. Leaders must challenge the status quo daily.

- Fostering Flexibility and Fluidity: Breaking down disciplinary silos is a critical early step if an institution is to respond to emerging opportunities--especially to 
emerging opportunities with the private sector. 9 In the new millennium, all universities are talking about multidisciplinary research, but most still lack the fundamentals-flexibility and fluidity-to react quickly to new initiatives as they emerge. Agility has not been the prevailing watchword, but it must become the mantra in order to exploit entrepreneurial opportunities. Barriers must be removed; agility enhanced.

- Crafting Innovation Communities:

Universities should promote the creation of "innovation communities," associations similar to the non-academic settings described by von Hippel in Democratizing Innovation. ${ }^{10} \mathrm{He}$ writes about innovation "nodes consisting of individuals or firms interconnected by information transfer links which may involve face-to-face, electronic, or other communication." If we can create public/private innovation communities-linking academic and other public sector expertise to complementary private sector expertise-it could turbocharge innovation. In the process, it could also reinvigorate relationships with local, state, and federal EcoDevo partners.

- Managing Conflicts: Public universities - by their very nature of being public-must operate in the open; transparency is crucial. Thus, potential or perceived conflicts of interest must be managed in an open, transparent manner to preserve institutional integrity in an entrepreneurial environment. We have only to look to the infamous Enron-Anderson duo; both had policies that should have managed conflicts of interest and brought problematic issues to the fore. ${ }^{11}$ The policies obviously didn't prevail. Universities should learn from these corporate fiascos, given that many university conflict of interest policies may be no better than those of Enron and Anderson. The efficacy of institutional policies must be frequently evaluated during privatization reinvention.

- Enhancing the Status of Commercialization: Support for an on-campus private enterprise culture is beginning to grow. Texas A\&M University took a major step recently when its Board of Regents-for the purpose of promotion and tenure-elevated the stature of patents and commercialization of university research to a level comparable to teaching, research, and service. ${ }^{12}$ This break from tradition should be the wave of the future, since it will finally reward, rather than penalize, faculty for being entrepreneurial. Coupled to the recruitment of wealth creating faculty, it should propel a change in institutional culture.

- Facilitating Risk-Taking: Taking risks is not common at public research universities. And while it might be nice to believe that most entrepreneurial activities could occur inside the hallowed halls, that is unlikely to be the case on most 
campuses. Six figure bonuses can raise the ire of non-participating faculty, particularly when such incentives are added to only a handful of state salaries. ${ }^{13}$ Moneylosing ventures would be worse: Heads would roll. Thus, entrepreneurial efforts are often best handled by university affiliated non-profit or for-profit entities. ${ }^{14}$ Moving risks and rewards offcampus is the safest bet.

\section{A New K-State Initiative: The}

\section{Commercialization Leadership Council}

Always exuberant, K-State is intentionally heading onto the wealth creation highway, hoping to build some logical predictability into its travels while anticipating potholes and detours along the way. Fostering and facilitating innovation via rational exuberance is the goal, but we'll accept irrational exuberance (the Mandel/Patton variety) if it gets us where we need to go. Cautious growth-emulating France and Germany ${ }^{15}$ - won't cut it.

K-State has been nurturing a more entrepreneurial culture on campus for a long time. That has become a top priority in the past few years. We have focused on the six principles listed earlier for creating an entrepreneurial university culture and they all require ongoing effort. As part of this growing institutional activity, K-State recently formed a policy/ oversight group - the Commercialization Leadership Council (CLC).

Formation of the CLC: The Boards of

Directors of the KSU Research Foundation (KSURF) and the National Institute for Strategic Technology Acquisition and Commercialization
(NISTAC) created the CLC at K-State. KSURF and NISTAC are both not-forprofit, 501(c)(3) corporations created to support K-State; KSURF protects, holds title, and licenses K-State intellectual property, and NISTAC facilitates the development of regional value propositions, including the launching of technology-based ventures.

CLC Membership: K-State administrators on the Boards of KSURF and NISTAC serve on the CLC, which is chaired by the Provost. Table 1 below lists the membership. Other CLC members include the presidents of NISTAC, the KSU Foundation, Kansas Technology Enterprise Corporation (KTEC), and Manhattan Area Chamber of Commerce, and the Manhattan city manager. KSURF and NISTAC provide staff to the CLC.

CLC Mission: To "facilitate commercialization activities involving university intellectual property, university infrastructure, university personnel, and/or other university resources. Inherent in its mission is providing leadership to enhance communication, coordination and leveraging of university, community, and other external assets and establishing university procedures whereby appro-priate affiliated not-forprofit and for-profit entities which provide a return on investment to the university may be created." The CLC is about entrepreneurship and wealth creation.

CLC Strategic Wealth Acquisition Targeting (SWAT) Teams: Venturespecific SWAT Teams represent the nucleus of CLC activities. As structured now, seven core members are included. 


\begin{tabular}{|l|l|}
\hline \multicolumn{2}{|l|}{ TABLE 1: COMmERCIALIZATION LeADERSHIP CoUNCIL } \\
K-STATE MEMBERS & \multicolumn{2}{l|}{ NON-UNIVERSITY MEMBERS } \\
\hline Provost / Vice President for Academic Affairs & NISTAC President* \\
Vice President for Administration \& Finance & KSU Foundation President \\
Vice President for Institutional Advancement* & KTEC President \\
Vice Provost for Research / KSURF President* & Manhattan Chamber of Commerce President* \\
Senior University Attorney & Manhattan City Manager* \\
Dean of Agriculture & \\
Dean of Arts and Sciences & \\
Dean of Business Administration & \\
Dean of Engineering & \\
Dean of Veterinary Medicine & \\
\hline
\end{tabular}

\begin{tabular}{|l|l|}
\hline \multicolumn{2}{|c|}{ TABLE 2: VentURE-SPECIFIC SWAT TEAMS } \\
CORE MEMBERS
\end{tabular}

(five from the $\mathrm{CLC}^{*}$ ) with significant variability possible among the venturespecific members. The SWAT Team efforts are led by the K-State Vice President for Institutional Advancement. NISTAC, KSURF, and the colleges provide SWAT staff. A key element of any SWAT team is its ability to assemble particular expertise required for a specific venture. And because these ventures could roll out of the university or be recruited externally, the skill sets are highly variable. Thus, flexibility is crucial. Figure 1, page 49, illustrates where these skills may be acquired though the list is not exhaustive.

An overall operational schematic for the CLC is also depicted in Figure 1. KSURF and NISTAC provide necessary staffing, and the K-State colleges are primary stakeholders and providers of IP and expertise for ventures. External ventures are also facilitated.

CLC Strategic Leveraging of Resources: Universities must be thoughtful and strategic in acquiring resources for any purpose, including (and, perhaps, especially) resources for commercialization ventures. The stakeholder makeup of the CLC is designed to ensure that the required resources are leveraged in a coordinated fashion, not haphazardly.

CLC Wealth Creation: K-State must realize substantial returns on investment if this new initiative with the CLC is to be a success. The efforts must create wealth for the institution to cover the 
costs of privatization and to grow the financial bottom line appreciably.

Big numbers will be needed for faculty as well, perhaps on the order of the now-dated chapter "Getting by on $\$ 875,000$ a Year" in The Wall Street Journal Book of Chief Executive Style. ${ }^{16}$ Entrepreneurial faculty must have access to fractional appointments (partially inside the university, partially outside), where a "sky's the limit" income philosophy prevails on the nonuniversity side. The goal is no longer a living wage or some level of enhanced living wage for faculty. The new objective is prosperity.

In the spirit of rational exuberance, equity positions in innovation-driven ventures are likely to be where the most significant returns of investment can be generated. CLC members are in discussion with a number of major corporations about joint startup ventures, and we anticipate that these will be a major near-term focus. Some may involve only university-generated IP, but corporate IP is likely to be linked to most such ventures.

\section{In Search of Rainbows ... and Bullion- Laden Vessels}

Finding a pot of gold isn't easy regardless of where the search for it takes place. However, any sane individual working inside academe would deem it hopeless to find one buried at a public university. The Ivory in the Towers has worn thin after decades of under-funding; any reserves were depleted long ago. So why even bother digging for ingots?

K-State is trying a new approach with the CLC - we're not searching for obscure pots of gold; we're scanning the horizon for rainbows. They're rare but easier to spot. The CLC is attempting to identify the most inspired, multihued success stories-the clusters of IP, the natural innovation communities, the leading multidisciplinary research arenas, the unique analytical servicesto then structure innovation ventures on the foundations they provide. By doing so, the CLC expects to harvest the occasional bullion-laden vessel.

The Click's role after sanctioning the venture is to support risk-taking, while attempting to manage the risks taken and zealous type-A folks taking them. The tasks are nontrivial.

Time will tell whether K-State's rational exuberance tactics will generate the sought after revenues. But, we hope not too much time. Privatization resources are needed now!

\section{References}

1. Trewyn, R.W. "Research Challenges in Changing Times: Lead, Follow, or Get Out of the Way," in Riding the Momentum of Research: Leadership Challenges in Public Research Universities, 2004, Merrill Advanced Studies Center, University of Kansas, MASC Report No. 108, 63-72.

2. Trewyn, R.W. "Recruiting and Training Future Scientists: Converting Intellectual Capital into Intellectual Property," in Recruiting and Training Future Scientists: How Policy Shapes the Mission of Graduate Education, 2003, Merrill Advanced Studies Center, University of Kansas, MASC Report No. 107, 51-58.

3. Fox, Marye Anne. "Impact of the Marketplace on the Financial Stability of American Public Research Universities," in Reinventing the Research University, 2004, (Edited by: Luc E. Weber and James L. Duderstadt), Economica, London, Paris, Genéve, 197-212.

4. Fischer, Karin. "Colorado Institute Folds After 6 Years," 2006, Chronicle of Higher Education, Volume 52, Issue 36, A33.

5. Mandel, Michael J. Rational Exuberance: Silencing the Enemies of Growth and Why the 
Future is Better Than You Think. 2004, Harper Collins Publishers, Inc., New York, NY.

6. Ibid, 12.

7. Axelrod, Alan. Patton on Leadership: Strategic Lessons for Corporate Warfare, 1999, Prentice Hall Press, Paramus, NJ, 74.

8. Shiller, Robert. Irrational Exuberance, 2000, Princeton University Press, Princeton, NJ.

9. Trewyn, R.W. “Graduate Education and Research in the Year 2000: Fashioning Horizontal Flexibility in a Vertical World," in Building Cross-University Alliances that Enhance Research, 1999, Merrill Advanced Studies Center, University of Kansas, MASC Report No. 103, 59-68.

10. von Hippel, Eric. Democratizing Innovation, 2005, MIT Press, Cambridge, MA, 93-106.

11. Goldsmith, Marshall. "Challenge Up: A Key to Organizational Integrity," in Leadership and
Governance from the Inside Out, 2004, (edited by: Robert Gandossy and Jeffrey Sonnenfeld), John Wiley \& Sons, Inc., Hoboken, NJ, 83-87.

12. Jaschik, Scott. "Teaching, Research, Service \& Patents," Inside Higher Ed News, via insidehighered.com, May 30, 2006.

13. Carlisle, Nate. "University Releases RADIL Bonus Amounts," Columbia Daily Tribune, Columbia, MO, March 1, 2005.

14. Trewyn (2004) and Trewyn (2003) include more detailed descriptions.

15. Mandel (2004), 10.

16. Diamond, David, Bryan Burrough, Cathy Crimmins, Stephen Fenichell, John Marchese, Sara Nelson, James P. Sterba, and Mary Walton, The Wall Street Journal Book of Chief Executive Style, 1989, William Morrow and Company, Inc., New York, NY, 173-187. 


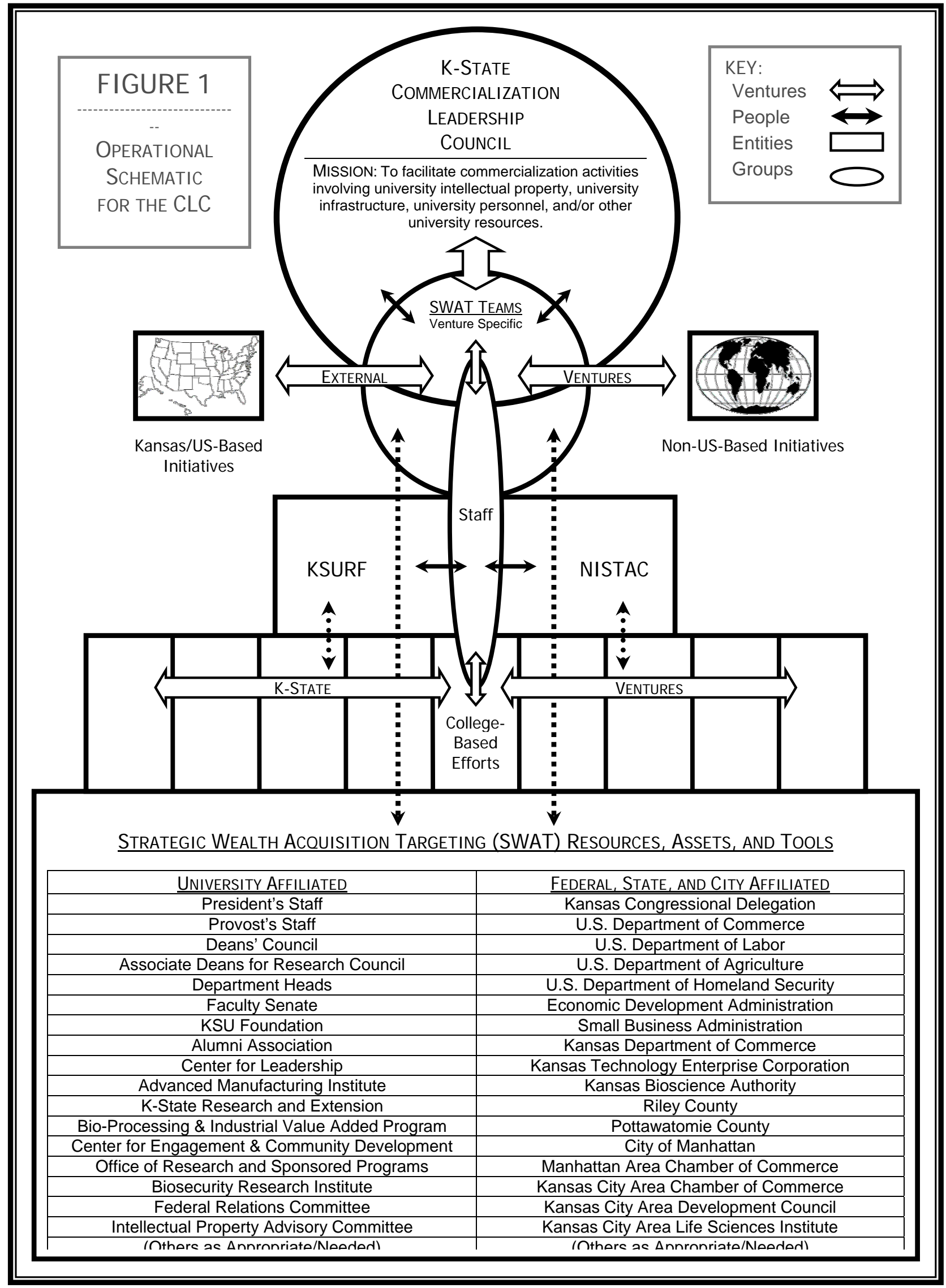

